\title{
Aktualisasi Kepemimpinan Astha Brata Dalam Era Millenial
}

\author{
Imam Sutarjo \\ Universitas Sebelas Maret \\ imamsutardjo_uns@yahoo.co.id
}

\section{Article History}

received $1 / 9 / 2021$

\author{
revised 1/10/2021 accepted 1/11/2021
}

\begin{abstract}
The teachings of astha brata leadership inherited from our ancestors are contained in old texts and are often presented in wayang shows, in this millennial era less and less known and unknown to the next generation of the nation's children. So it is very feared that the heritage of local wisdom values will be lost in the motherland. The purpose of this paper is to examine, express and actualize the concept of astha brata leadership in order to keep it alive, develop and be applied in the Unitary State of the Republic of Indonesia, on the basis of Pancasila, the 1945 Constitution and Bhinneka Tunggal Ika. In this study, a comparative approach is taken about Astha Brata's leadership through the Ramayana, Serat Ajipamasa, and the wayang story of Wahyu Makutharama. The method applied is content analysis, which includes the analysis of differences in content and personification in Astha Brata leadership. The results of the discussion, the task of a leader is to serve others, serve the people/people or others. The leadership of astha brata in the Ramayana was given/taught by Prabu Rama to Raden Bharata (his younger brother) and to Gunawan Wibisana (Ravana's younger brother); that a leader holds to 8 (astha = eight) brata (character / character, action) eight gods. In Serat Ajipamasa, the leadership of Astha Brata was taught by Prabu Ajipamasa (Kusumawicitra) to Sang Gandakusuma and Jayasusena, that a good leader adheres to the 8 (eight) contents of the world.
\end{abstract}

Keywords: actualization, leadership, astha brata, millennial

\begin{abstract}
Abstrak
Ajaran kepemimpinan astha brata warisan nenek moyang kita yang tertuang dalam naskahnaskah lama dan sering disajikan dalam pertunjukan wayang, pada era mellenial ini semakin kurang dikenal dan tidak dipahami generasi muda penerus anak bangsa. Sehingga sangat dikhawatirkan warisan nilai-nilai kearifan lokal akan hilang di bumi pertiwi. Tujuan tulisan ini mengkaji, mengungkapkan dan mengaktualisasikan konsep kepemimpinan astha brata agar tetap hidup, berkembang dan diterapkan di Negara Kesatuan Repubik Indonesia, dengan dasar negara Pancasila, UUD 1945 dan Bhinneka Tunggal Ika. Dalam kajian ini dilakukan pendekatan komparatif tentang kepemimpinan astha brata melalui kitab Ramayana, Serat Ajipamasa, dan cerita wayang Wahyu Makutharama. Metode yang diterapkan adalah content analysis, meliputi analisis perbedaan isi dan personifikasi dalam kepemimpinan astha brata. Hasil pembahasan ditemukan bahwa kewajiban seorang pemimpin adalah pelayan orang lain, pelayan umat/rakyat atau sesama. Kepemimpinan astha brata dalam Ramayana diberikan/diajarkan Prabu Rama kepada Raden Bharata (adiknya) dan kepada Gunawan Wibisana (adik Rahwana); bahwa seorang pemimpin hendaknya berpegang kepada 8 (astha = delapan) brata (watak/sifat, karakter, action) delapan dewa. Dalam Serat Ajipamasa kepemimpinan astha brata diajarkan oleh Prabu Ajipamasa (Kusumawicitra) kepada Sang Gandakusuma dan Jayasusena, bahwa pemimpin yang baik berpegang kepada 8 (delapan) isi dunia.
\end{abstract}

Kata kunci: aktualisasi, kepemimpinan, astha brata, millenial

Social, Humanities, and Education Studies (SHEs): Conference Series https://jurnal.uns.ac.id/shes

p-ISSN 2620-9284 e-ISSN 2620-9292 


\section{PENDAHULUAN}

Ajaran kepemimpinan astha brata dalam masyarakat Jawa sering terdengar dalam pertunjukan wayang dan ditulis dalam naskah-naskah lama warisan nenek moyang, leluhur bangsa. Sehingga penelitian terhadap naskah lama amat menarik, sebab dalam teks tersebut apabila dikaji memberikan informasi yang amat luas dan mendalam mengenai kehidupan masa lampau. Berbagai peninggalan karya sastra yang berupa naskah dan tersebar di seluruh tanah air itu pada hakikatnya merupakan kekayaan intelektual dan cagar budaya nasional. Dalam pertunjukan wayang dan sastra lama/klasik tersebut merupakan bentuk komunikasi antara pengarang dengan masyarakat pembacanya, yang berupa konsep-konsep (pertanda) dan merupakan penanda harapan masyarakat. Oleh karena itu, naskah atau karya sastra diciptakan pada dasarnya bukan sekedar dihayati isinya, tetapi dalam rangka alternatif untuk membentuk kepribadian pembaca (masyarakat) agar hidupnya semakin utama dan berbudi luhur (Teeuw, 1983:7-8).

Masyarakat dapat mengetahui isi karya sastra lama (naskah) apabila telah dikaji, diteliti dan diungkapkan isinya. Maka dari itu, naskah-naskah lama yang berisi nilai-nilai, cita-cita, aturan-aturan, pegangan dan pedoman hidup; wajib diteliti dan diungkapkan serta dideskripsikan isinya agar dapat dimanfaatkan oleh masyarakat dalam menata kehidupannya. Hal tersebut perlu dilakukan karena amat berguna untuk menunjang usaha-usaha pembinaan jiwa dan pengembangan kepribadian (Darusuprapta, 1985: 138), dan dalam rangka ikut mensukseskan pembangunan bangsa dan negara. Mengingat berbagai peninggalan sastra lama (naskah), pertunjukan wayang tersebut merupakan bagian dari budaya nasional. Hakikat budaya nasional identik dengan pembangunan nasional, dan pembangunan nasional hakikatnya merupakan pembangunan manusia Indonesia seutuhnya, secara adil, merata; baik jasmani maupun rohani berdasarkan Pancasila dan Undang-Undang Dasar 1945.

Berdasarkan kondisi dan keberadaan serta pentingnya mengkaji sastra lama tersebut, makalah ini berusaha mengkaji dan mengungkap "aktualisasi kepemimpinan astha brata dalam era millennial", agar nilai-nilai budaya tradisi menjadi dekat, akrab dengan masyarakat terutama generasi millenial. Mengingat jaman millenial dewasa ini generasi muda sangat kompetensi terhadap IT, dan dunia maya; tetapi cenderung tidak tertarik dan tidak paham terhadap nilai-nilai lokal budaya sendiri (Iocal wisdom). Generasi millenial telah terbentuk dan berorientasi terhadap wawasan budaya global, sehingga berbagai nilai luhur bangsa cenderung ditinggal, salah satunya termasuk nilai kepemimpinan astha brata. Mengingat kepemimpinan yang baik akan menentukan keberhasilan pembangunan nasional.

\section{KAJIAN TEORI}

Kepemimpinan sangat berkaitan dengan pemimpin, yang pada hakikatnya adalah seseorang yang mempunyai kemampuan untuk mempengaruhi perilaku orang lain di dalam kerjanya dengan menggunakan kekuasaan. Dan kekuasaan merupakan kemampuan untuk mengarahkan dan mempengaruhi bawahan sehubungan dengan berbagai tugas yang harus dilaksanakan dan diselesaikan (Nanang Fattah, 2001:88). Setiap manusia pada hakikatnya adalah pemimpin, minimal memimpin dirinya sendiri; bahkan sebagai pemimpin keluarga, masyarakat, bangsa dan pemimpin negara; sehingga keteladanan pimpinan dalam berbagai sektor sangat dibutuhkan dan amat menentukan keberhasilannya. Terlebih pemimpin bangsa yang dapat diteladani (ing ngarsa sung tuladha) dapat menimbulkan kesadaran dan perilaku individu maupun kolektif, selaras dengan prinsip-prinsip kepemimpinan yang disepakatinya. Keadaan tersebut dapat merupakan kekuatan besar dan dambaan bersama dalam rangka menciptakan bangsa yang jaya, berwibawa, berbudaya dan beradap, jauh dari berbagai watak biadab. 
Pemimpin adalah pribadi, individu manusianya, dan kepemimpinan adalah sifat yang melekat kepadanya sebagai pemimpin. Kepemimpinan bukanlah sebuah "kekuasaan", melainkan sebuah tugas, tanggung jawab, dan pengorbanan. Syarat pemimpin dan kepemimpinan minimal ada 4 (empat), yaitu :

1. Adanya pengikut atau pendukung, dan pengikut ini yang selalu membantu segala program kerja, visi dan misi yang akan ditempuh.

2. Pemimpin efektif bukanlah selalu seseorang yang dipuja atau dicintai, namun mereka adalah individu yang menjadikan para pengikutnya untuk berbuat benar. Karena kepemimpinan berbeda dengan popularitas, namun kepemimpinan identik dengan pencapaian tujuan/hasil.

3. Pemimpin adalah mereka yang sangat tampak; oleh karena itu, mereka harus memberikan keteladanan (contoh)

4. Kepemimpinan bukanlah kedudukan, jabatan, atau uang. Kepemimpinan adalah tanggung jawab. Sehingga tidaklah mudah seorang pemimpin untuk melaksanakan tugas-tugas kepemimpinannya.

Kepemimpinan Negara Kesatuan Republik Indonesia amat dipengaruhi oleh kekuasaan raja sebelumnya, mengingat di nusantara ini dahulu berdiri negara-negara besar dan berwibawa, misalnya kerajaan: Singasari, Majapahit, Demak, Pajang, Mataram. Kerajaan yang amat berpengaruh terhadap konsep-konsep kepemimpinan dewasa ini adalah raja Mataram Islam (Sultan Agung). Raja benar-benar amat berkuasa, dan kebesaran dari kekuasaan tersebut terlihat dan tercermin pada: (a) gelar sang raja yang disandangnya, (b) legitimasi dengan mitos, dan (c) kepemilikan atau pengumpulan pustaka.

Dalam hal hukum, raja Mataram adalah pembuat dan pelaksana (pengendal) hukum itu sendiri. Raja menjadi hakim tertinggi, yang sering menghukum mati siapa saja yang dianggap melakukan kesalahan besar terhadap raja. Kebesaran kekuasaan raja yang tak terbatas tersebut, maka raja sering disebut : gung binathara, nyakrawati ambau dhendha (kekuasaannya amat besar laksana dewa, pemelihara hukum dan penguasa dunia). Maka raja dikatakan wenang murba hamisesa wong sanagara (berkuasa di seluruh negeri, berwenang menguasai dan mengendalikan semua rakyat).

Kepemimpinan dalam budaya Jawa bersifat absolut, penguasa tunggal. Raja bukan saja pembuat hukum, bahkan ia sendiri adalah hukum. Raja bukan sekedar pemimpin kerajaan atau negara, tetapi ia sendiri adalah negara. Konsep kekerasan dan kesewenang-wenangan tersebut harus dilakukan oleh seorang pemimpin atau raja pada waktu itu, karena untuk menjawab berbagai persoalan kemasyarakatan pada masa itu memang keras dan harus mengandalkan kekuatan; hukum rimba yang berlaku, sehingga siapa yang kuat akan selalu berkuasa dan menindas yang lemah, sebagai akibatnya keadilan belum terpikirkan. sejarah menunjukkan bahwa power tends to corrupt, absolute power tends to corrupt absolutely 'kekuasaan cenderung korup, dan kekuasaan absolut cenderung korup secara absolut pula' (Action dalam Moedjanto, 2001:xxiii).

Konsep kesewenang-wenangan tersebut setelah pengaruh Islam yang dibawa oleh para wali atau wali sanga masuk di tanah Jawa, Konsep absolut tersebut cenderung memudah, dan lebih menuju kepada rahmatan lil alamin; yaitu pemimpin atau raja harus menjadi penasehat, teladan, pengayom, pelindung negara dan rakyat. Bahkan dalam penobatan raja pun diperlukan restu dari ulama atau walisanga, sehingga gelar raja-raja Jawa dinasti Mataram Islam menggunakan gelar Susuhunan, terkecuali Sultan Agung Hanyakrakusuma. Pengaruh Islam ini selain terlihat dalam konsep pemberian gelar seorang raja, juga dalam konsep-konsep kepemimpinan seorang raja dalam mengatur negara atau kerajaan. 


\section{METODE}

Di SOLORARAYA berdiri kerajaan Kasunanan Surakarta Hadiningrat dan Pura Mangkunegaran, yang menyimpan dan memiliki berbagai naskah lama yang tersimpan di Perputakaan Sanapustaka (karaton Surakarta), Perpustakaan Reksapustaka Mangkunegaran, dan Museum Radyapustaka Sriwedari. Tempat pertunjukan wayang juga banyak, yaitu di RRI Surakarta, Wayang Orang Sriwedari, Taman Budaya Jateng di Surakarta, dan Balai Kambang. Sumber data dan data penulisan makalah ini adalah buku Ramayana, Serat Ajipamasa karya R.Ng. Ranggawarsita, dan naskah pertunjukan wayang cerita Wahyu Makutharama, karya Ki Wignyasutarno. yang terdapat dalam antawacana atau catur (dialog).

Teknik pengumpulan data dengan content analysis atau teknik catat yang berdasarkan dokumen atau naskah pertunjukan wayang purwa lengkap yang berisi tentang kepemimpinan. Analisis data menggunakan analisis interaktif, yang mencakup 3 (tiga) komponen; yaitu: reduksi data, sajian data dan verifikasi atau kesimpulan. Kegiatannya dilakukan dalam bentuk interaktif dengan proses pengumpulan data sebagai suatu proses "siklus" dari ketiga komponen di atas (Miles \& Huberman dalam Sutopo: 1992).

\section{HASIL DAN PEMBAHASAN}

Kepemimpinan astha brata diungkapkan oleh para pujangga dalam Kakawin Ramayana, Serat Ajipamasa, dan cerita wayang Wahyu Makutharama. Adapun isinya sebagai berikut.

\section{Kakawin Ramayana}

Pokok-pokok ajaran astha brata Kakawin Ramayana dijelaskan pada pupuh atau sargah ke-24 yang terdiri dari 260 bait itu terdapat episode astha brata. Episode ini menceritakan suatu ajaran yang diberikan oleh Rama kepada Bharata (adiknya, pupuh 3) dan kepada Wibhisana yang dinobatkan menjadi raja di Alengka, menggantikan kakaknya yang meninggal, dikalahkan oleh Rama. Adapun nasihat ajaran astha brata itu merangkum perlambangan watak dan kepribadian pemimpin negara yang utama dengan berpedoman kepada perilaku delapan dewa, dalam mengatur negara seisinya.

Kedelapan perilaku para dewa yang perlu diteladani dan diterapkan para pemimpin dalam mengatur negara dan melayani orang lain, raja/pemimpin berwatak seperti.

a. Dewa Indra dilukiskan: ia menghujankan kepuasan kepada dunia dan hendaknya kedermawananmu sebagai hujan membanjiri dunia sehingga membuat seluruh dunia sejahtera dengan dana dari raja.

b. Dewa Yama dilukiskan: perilaku Hyang Yama menghukum yang berbuat jahat. la memukuli pencuri apabila mereka telah mati. Anda sebaiknya ikut memukul segala yang berbuat salah. Siapa saja yang mengganggu dunia, bunuhlah.

c. Batara Rawi atau Surya dilukiskan: Hyang Rawi atau Surya mempunyai tabiat mengisap air tiada henti-hentinya secara perlahan-lahan olehnya. Demikianlah hendaknya anda patut mencontohnya sampai menemukannya. Janganlah tergesa-gesa, begitulah Suryabrata.

d. Hyang Candra atau Bulan dilukiskan: Perilaku Hyang Candra menggembirakan seluruh dunia. Tingkah laku hendaknya lemah lembut dipandang orang. Gelak anda hendaknya manis seperti amreta. Setiap orang arif termasuk pendeta patut dihormati.

e. Hyang Bayu atau Angin dilukiskan: hendaknya seperti Dewa Angin apabila anda mengintai segala perbuatan. Seharusnya anda mengetahui semua pikiran rakyat. Mata-mata yang baik itulah merupakan mata anda akan tetapi tidak kelihatan. Itulah Bayuputra, sangat gaib dan mempunyai sifat-sifat yang luhur. 
f. Hyang Kuwera dilukiskan: mengecap segala kenikmatan sambil bersenangsenang, tidak berjangka dengan makan dan minum. Juga dalam hal bersandang, berpakaian dan berhias. Perilaku Hyang Kuwera yang patut ditiru.

g. Hyang Baruna dilukiskan: perilaku Dewa Baruna memegang senjata Nagapaca yang sangat berbisa, adalah alat untuk mengikat. Itulah yang patut anda contoh, yaitu Pacabrata. Andalah yang patut mengikat segala penjahat.

h. Hyang Agni dilukiskan: selalu membakar musuh, itulah perilaku Dewa Agni. Kegalakan anda kepada musuh, itulah apinya. Barangsiapa yang anda dekati, hancur lebur. Itulah yang disebut Agnibrata.

\section{Serat Ajipamasa}

Ajaran kepemimpinan astha brata adalah pemimpin dalam melaksanakan tugas memahami mikrokosmos dan makrokosmos, serta berpegang pada 8 anasir bumi, yaitu berwatak : tanah, api, air, angin, matahari, bulan, bintang, dan awan. Hal tersebut diajarkan oleh Prabu Ajipamasa (Kusumawicitra) kepada Sang Gandakusuma dan Jayasusena, terdapat pada tembang Girisa bait 2-14; bahwa pemimpin dalam mengaplikasikan hendaknya memiliki ambeg atau watak:

a. Pratala 'Tanah', maksudnya seorang pemimpin hendaknya selalu bersedekah atau memberi, selalu membuat senang orang lain dan ikhlas dalam berbuat, tidak pernah dendam dan sakit hati meskipun dicangkuli, dibuangi kotoran, diinjak-injak.

b. Tirta 'Air', maksudnya seorang pemimpin hendaknya selalu bersifat pemaaf terhadap siapa saja, dan selalu membuat ketentraman serta kedamaian terhadap semua manusia atau rakyatnya.

c. Dahana 'Api', maksudnya seorang pemimpin selalu menjaga kewibawaan dan aib negara, menghilangkan kotoran bumi hingga lenyap seluruh kejahatan. Selalu membuat terang dan tidak merugikan orang lain, sabar dalam meraih cita-cita, tidak tamak, dan penuh semangat dalam menjalankan tugas.

d. Maruta 'Angin', maksudnya seorang pemimpin hendaknya selalu waspada, selalu mengamati kepribadian dan perbuatan orang lain (rakyatnya), dapat berbaur dengan siapa saja dan dimana saja (blusukan). Besar kecil tercakup, segala perbuatannya untuk orang lain, jauh dari berbagai maksud pribadi, bermanfaat bagi siapa saja, tidak sakit bila dicemooh orang lain.

e. Surya 'Matahari', maksudnya seorang pemimpin harus sabar dalam menjalankan tugas dan kewajiban, serta berhati-hati, selalu memberi motivasi atau semangat rakyat, memberi penerangan/pencerahan serta tidak mudah putus asa.

f. Candra 'Bulan', maksudnya seorang pemimpin hendaknya dapat membuat kedamaian, ketentraman, dan kesenangan hati rakyat, sabar, tidak kejam, berperilaku halus, serta semangat berbelas kasih kepada sesama.

g. Sudama 'Bintang', maksudnya seorang pemimpin bersifat sopan santun, teguh pendirian, tidak mudah terpengaruh dan terkena godaan, berkemauan mantap, penuh kepercayaan tidak munafik, dan memberi petunjuk atau gemar memberi petuah kepada segenap anak buah dan rakyat.

h. Mendhung 'Awan', maksudnya pemimpin harus berwibawa, dapat mengendalikan bangsa dan negara, adil dalam menegakkan kebenaran, dan senang menolong serta membantu rakyat.

\section{Cerita Wahyu Makutharama}

Dalam cerita wayang ini ajaran kepemimpinan astha brata diberikan Prabu Kresna dengan menyamar (ganti rupa) seorang brahmana bernama Begawan Kesawasidhi kepada Raden Arjuna : Adapun isi nasihatnya di bawah ini.

Begawan Kesawasidhi : Kulup, mangkene mungguh wijange. Marma ingaran astha brata, astha iku wolu, brata iku laku. Laku wewolu kang tuwuh saka gumelaring jagad iki, kang dadi dhasar paugeraning narendra/pemimpin. Lire narendra/pemimpin kudu bisa netepi wataking: 
a. Surya; dayane panas, nanging sakabehing tindak lan pranatane bisa dadi sumber panguripan lan kamulyaning para kawula. Kajaba iku sakehing kekucah panjenenganing nata marang saisining praja, nora kaworan rasa pangarep-arep tumraping piwales.

b. Rembulan; lire bisa weh pepadhang samangsa praja nandhang pepeteng, sarta tansah bisa akarya ayeming atine wong sanagara, kanthi reh pakarti kang tansah bisa hangayomi para kawulane kabeh.

c. Lintang; lire bisa dadi puser pasrening praja tumrap kasusilan lan kabudayan kang adi luhung, sarta kudu bisa dadi tepa palupi miwah pandom pancering keblate para kawula kabeh, mungguhing solah tingkah, laku patrap, apadene pangucap lan panembahe marang Kang Akarya Jagat.

d. Mendhung; yaiku bisa nandukake singit wingiting pangaribawa. Ananging tumanduke sakabehing reh olahing praja, kudu bisa dadi sarana kamulyan lan katentremaning para kawula.

e. Bumi; yaiku santosa ing budi, lire nora miyur kapanduk ing rembug manise kang hambeg para wadul. Kajaba iku sakabehing pangucap lan tumindak sabarang reh, kudu tansah suci lan nyata.

f. Samodra; jembar ing rasa budine, tan singget ing sesinggetan, tan pingget ing pepinggetan, miwah tansah kamot lan momot, sarta momong hamadhahi samubarang kahanan.

g. Geni; lire bisa matrapake pidana marang kang kudu kawisesa, nora mawas kulawarga, kulit daging, sakabehing piala lan memalaning nagara kudu kasirnakake dening pangwasaning nata kanthi adil, nora emban oyod emban cindhe bebasane. Nanging kosok baline pangwasaning nata kang sura sekti mau, kudu bisa migunani kanggo memayu hayuning para kawula ing lair lan batine.

h. Angin; lire bisa tumindak maratani marang saisining praja, kabeh papan bisa kasarawung lan kawuningan dening panjenenganing nata, temahan ora bakal tidha-tidha pamutuse marang sabarang prakara. Sarta kudu tansah mintir tan ana pedhote anggone manggalih lan tumindak kanggo kamulyaning para kawula.

\section{SIMPULAN}

Ajaran kepemimpinan astha brata yang tersurat dan tersirat di dalamnya ternyata masih aktual dan relevan apabila diterapkan oleh seorang pemimpin untuk mengatur kehidupan keluarga, masyarakat, dunia kampus, bangsa dan negara. Maka dari itu, ajaran kepemimpinan tersebut terus dilestarikan, dikembangkan dan diaktualisasikan di bumi pertiwi NKRI dan dapat dijadikan salah satu alternatif untuk diaplikasikan di negara Indonesia ini, agar menjadi negara yang besar, kuat, patuh hukum, berwibawa, berjati diri bangsa sendiri dan mandiri.

Tingkatan kepemimpinan ada 3 yaitu, nistha, madya, dan utama. Konsep atau ajaran kepemimpinan astha brata ini merupakan wajibing ratu, pangagem, pambegan, dan lelabuhaning ratu (kewajiban, pakaian, watak, jasa) seorang pemimpin dalam melayani sesama/rakyat, mengatur bangsa dan negara; dengan berprinsip kepada watak 8 (delapan) dewa atau 8 (delapan) anasir/isi dunia ini..

\section{DAFTAR PUSTAKA}

Darusuprapta. (1985). Serat Wulang Reh. Surabaya: Citra Jaya. Geertz, Clifford.(1969). The Religion of Jawa. New York: The Free Press.

Imam Sutardjo. (2006). "Kemerdekaan Ri: Prediksi Pujangga Ranggawarsita" dalam buku Mutiara Budaya Jawa. Surakarta : Jurusan Sastra Daerah FSSR UNS.

(2008). Kreativitas Pujangga Ranggawarsita dalam Inovasi Penciptaan Sastra Kapujanggan pada Jaman Surakarta Awal, Makalah Seminar Internasional. Dies Natalis ke-62 Fakultas IImu Budaya, 16 Mei 2008, UGM Yogyakarta. 
Kamajaya. (1980). Lima Karya Pujangga Ranggawarsita (Kalatidha, Sabdajati, Sabdatama, Jakalodhang, Wedharaga). Jakarta : Departemen P dan K.

Mulyo Hutomo. (1985). Serat Aji Pamasa (Alih Aksara dari huruf Jawa ke huruf latin). Reksapustaka No. B 6a. Semarang : Departemen P dan K Proyek Pengembangan Perpustakaan Jawa Tengah.

Noriah Mohamed. (1993). Jayengbaya : Memahami Pemikiran Orang Jawa. Malaysia: Universiti Kebangsaan Malaysia.

Padmosoekotjo. (1960). Ngengrengan Kasusastran Jawa I, II. Yogyakarta: Hien Hoo Sing.

Poerbatjaraka dam Tardjan Hadidjaja. (1952). Kepustakaan Djawa. Jakarta/ Amsterdam : Djambatan.

Ras. (1983). Bunga Rampai Sastra Jawa Mutakhir. Jakarta : Grafiti Press.

Robson. (1978). "Pengkajian Sastra-sastra Tradisional" dalam Bahasa dan Sastra Tahun IV No.6. Jakarta : Departemen P dan K.

Serat Ajipamasa (Manuskrip). Tt. Nomor Katalog B 6a. Surakarta: Koleksi Purpustakaan Reksapustaka Mangkunegaran.

Subalidinata. (1981). Seluk Beluk Kesastraan Jawa. Yogyakarta: Keluarga Mahasiswa Sastra Nusantara Fak. Sastra dan Kebudayaan UGM.

Teeuw, A. (1983). Membac 